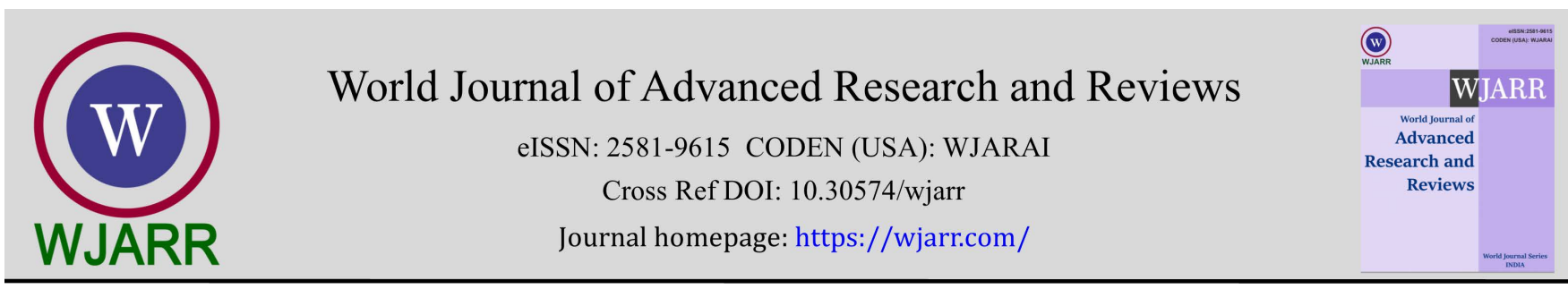

(CASE REPORT)

Check for updates

\title{
Course of recovery in COVID-19 patients with pre-existing post Koch's sequelae
}

\author{
Manali Ganesh Sonavane, Snehal Sunil Sawant *, Jyotsna Amod Thosar, Jaimala Vijay Shetye \\ PT School \& Centre, Seth G S Medical College and KEM Hospital, Parel, Mumbai-12, Maharashtra, India.
}

World Journal of Advanced Research and Reviews, 2021, 10(03), 113-120

Publication history: Received on 28 April 2021; revised on 06 June 2021; accepted on 08 June 2021

Article DOI: https://doi.org/10.30574/wjarr.2021.10.3.0256

\begin{abstract}
Coronavirus disease 2019 (COVID-19) caused by SARS-CoV-2 predominantly causes respiratory disease in the form of viral pneumonia. Susceptibility to SARS-CoV-2, its progression and severity increases with presence of latent or active pulmonary tuberculosis (PTB). PTB is a highly prevalent respiratory disease in India. This case series explains the rehabilitation and course of recovery in ICU of two COVID-19 patients with post PTB sequelae. Both the cases showed safe and timely recovery due to appropriate and early physiotherapy intervention which needed modification in accordance with the medical management. However, their reduced functional capacity on pre-discharge assessment highlights the need for continuing pulmonary rehabilitation.
\end{abstract}

Keywords: COVID-19; Pulmonary TB; Physiotherapy; Rehabilitation

\section{Introduction}

Severe acute respiratory syndrome-Coronavirus 2 (SARS-CoV-2) is a newly emergent corona virus which predominantly causes respiratory disease in the form of viral pneumonia known as COVID-19 [1].Its common symptoms include fever, dry cough, fatigue, dyspnea along with headache, expectoration, diarrhea, vomiting and hemoptysis [2,3]. The dominant feature of COVID-19 is arterial hypoxemia seen due to ventilation perfusion mismatch[4]. Susceptibility to SARS-CoV-2 increases with presence of latent or active pulmonary tuberculosis (PTB) [5]. PTB is a highly prevalent respiratory disease in India [6]. COVID and PTB both primarily affect the lung and interfere with host immunity. Patients with PTB even after complete anti-Koch's treatment (AKT) may develop respiratory infection and lung disease which may become chronic leading to morbidity and mortality [7]. A previous respiratory disease impairs the patient's lung function, reduces their resistance to virus and they tend to develop Acute respiratory distress syndrome (ARDS) [8]. Active PTB also predicts worst outcome in patients affected with SARS-CoV-2 [5]. A possible cause for this is the immune-depression of the patient with advanced PTB along with the possible impairment of immune system due to SARS-CoV-2 [9]. A rapid systemic review by Gao Ya et al shows that TB is associated with a 2.1-fold increased risk of severe COVID-19 disease [10]. A recent study from China reported that patients with active or latent TB have increased susceptibility for SARS CoV-2 infection associated with rapid progression and severe involvement while a case of coinfection from China reported a good SARS-CoV-2 outcome [5]. The first ever global cohort study by global tuberculosis network also highlights the increased risk of these patients for covid-19 [11]. Thus, this area definitely requires further research to understand the role played by PTB sequelae. Post PTB sequelae is a pathological state that is caused by many patho-anatomical changes that occur in the healing process of PTB and can result in an obstructive, restrictive or a mixed pattern of impaired pulmonary function. Thus, Mycobacterium tuberculosis-infection can cause more rapid and severe COVID-19 disease progression $[5,12]$.

The following case series is based on the patients admitted in COVID-19 Intensive Care Unit (ICU) of tertiary care hospital in Mumbai. Many studies have explained physiotherapeutic intervention in acute care setting following COVID-

\footnotetext{
${ }^{*}$ Corresponding author Snehal Sunil Sawant

Physiotherapy School and Centre, Seth G.S. Medical College and KEM, Parel, Mumbai-12, Maharashtra, India.
} 
19. However, there's limited literature on physiotherapy intervention in patients with COVID-19 with latent or active TB. This case series explains the rehabilitation along with the medical management and course of recovery of two COVID-19 patients with post PTB sequelae in ICU.

\section{Patient Information}

\subsection{Case 1}

A 26-year-old male, driver by occupation, with a past history of pulmonary Koch's 8 years back, had completed his AKT and had no residual functional impairment. He presented with complaints of breathlessness grade 3 on modified medical research council dyspnea scale (MMRC), cough, retrosternal chest pain due to cough and fever with chills for four days before admission. On admission, his oxygen saturation was $91 \%$ he was then put-on two liters of oxygen support by nasal prongs(NP) and was shifted to COVID-19 ICU when he tested positive for COVID-19 on rapid antigen test. Chest X-ray revealed non-homogeneous opacities in bilateral lung fields with consolidation (Figure 1) and Highresolution computed tomography (HRCT) showed patchy areas of ground glass opacities in sub-pleural region in bilateral upper and lower lobes of the lung. The investigations and physiotherapy details are as mentioned in table 1 and 2 .

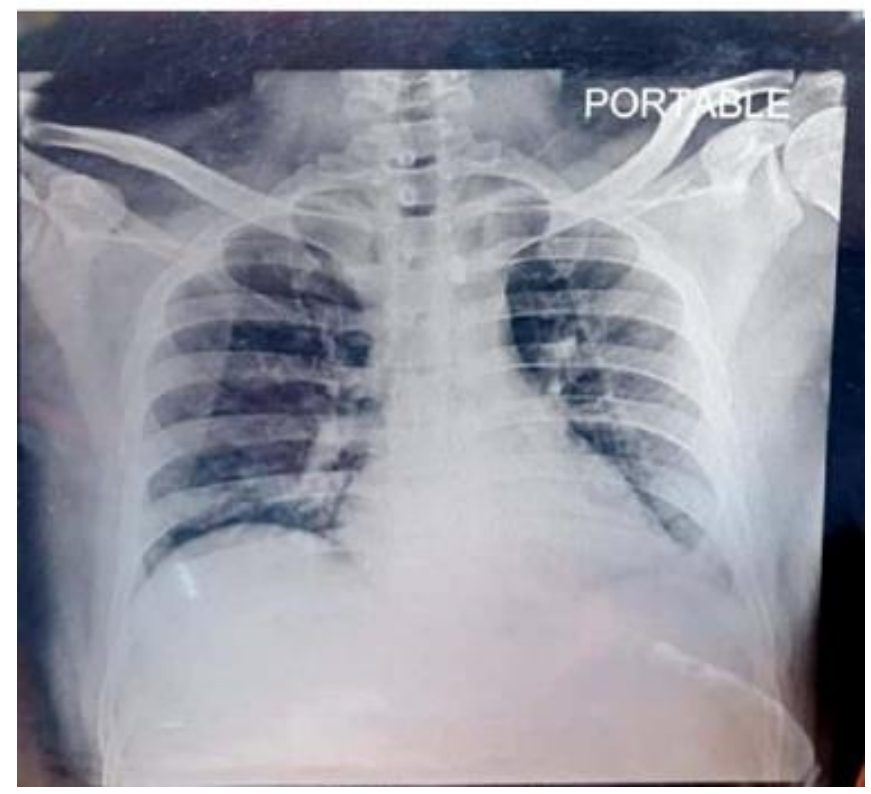

Figure 1 Chest X-ray [Case 1]

Table 1 Investigations

\begin{tabular}{|l|c|c|l|}
\hline Parameter & $\begin{array}{l}\text { Days after admission-out of 12 total } \\
\text { days }\end{array}$ & Results & Inference \\
\hline Haemoglobin & Day 1 & 14.2 & Normal \\
\cline { 2 - 4 } & Day 4 & 12.3 & Low \\
\hline Alkaline phosphate & Day 2 & 110 & Normal \\
\hline BUN & Day 2 & 13.6 & Normal \\
\hline D-Dimer & Day 2 & 0.90 & Normal \\
\hline LDH & Day 2 & 1.62 & Normal \\
\hline CRP & Day 2 & Normal \\
\hline
\end{tabular}

BUN-Blood urea Nitrogen; LDH-Lactate dehydrogenase; CRP- C reactive protein 
Table 2 Physiotherapy intervention and outcome measures

\begin{tabular}{|c|c|c|c|c|c|c|c|c|c|c|c|c|c|}
\hline $\begin{array}{l}\text { Session } \\
\text { number }\end{array}$ & & 1 & 2 & 3 & 4 & 5 & 6 & 7 & 8 & 9 & 10 & 11 & 12 \\
\hline 02 status & & $\begin{array}{l}2 \mathrm{~L} \\
\mathrm{NP}\end{array}$ & $\begin{array}{l}3 \mathrm{~L} \\
\mathrm{NP}\end{array}$ & $\begin{array}{l}8 \mathrm{~L} \\
\text { FM }\end{array}$ & $\begin{array}{l}5 \mathrm{~L} \\
\mathrm{FM}\end{array}$ & $\begin{array}{l}2 \mathrm{~L} \\
\mathrm{NP}\end{array}$ & $\begin{array}{l}2 \mathrm{~L} \\
\mathrm{NP}\end{array}$ & $\begin{array}{l}\text { Room } \\
\text { air }\end{array}$ & $\begin{array}{l}\text { Room } \\
\text { air }\end{array}$ & $\begin{array}{l}\text { Room } \\
\text { air }\end{array}$ & $\begin{array}{l}\text { Room } \\
\text { air }\end{array}$ & $\begin{array}{l}\text { Room } \\
\text { air }\end{array}$ & $\begin{array}{l}\text { Room } \\
\text { air }\end{array}$ \\
\hline \multicolumn{14}{|c|}{ Vitals } \\
\hline \multirow[t]{2}{*}{ Heart rate(HR) } & Pre & 93 & 78 & 75 & 84 & 88 & 87 & 83 & 95 & 96 & 95 & 96 & 95 \\
\hline & Post & 89 & 79 & 80 & 80 & 96 & 93 & 98 & 112 & 100 & 101 & 100 & 74 \\
\hline \multirow[t]{2}{*}{$\mathrm{Spo}_{2}(\%)$} & Pre & 90 & 92 & 99 & 98 & 96 & 95 & 94 & 98 & 99 & 98 & 99 & 96 \\
\hline & Post & 95 & 97 & 98 & 96 & 96 & 91 & 96 & 94 & 99 & 99 & 99 & 98 \\
\hline \multicolumn{14}{|c|}{ Physiotherapy Intervention } \\
\hline Positioning & & & & $\checkmark$ & $\checkmark$ & $\checkmark$ & $\checkmark$ & $\checkmark$ & $\checkmark$ & $\checkmark$ & $\checkmark$ & $\checkmark$ & $\checkmark$ \\
\hline $\begin{array}{l}\text { Breathing } \\
\text { Exercise }\end{array}$ & & & $\checkmark$ & $\checkmark$ & $\checkmark$ & $\checkmark$ & $\checkmark$ & $\checkmark$ & $\checkmark$ & $\checkmark$ & $\checkmark$ & $\checkmark$ & $\checkmark$ \\
\hline $\begin{array}{l}\text { Thoracic } \\
\text { expansion } \\
\text { exercise }\end{array}$ & & & & & $\checkmark$ & $\checkmark$ & $\checkmark$ & $\checkmark$ & $\checkmark$ & $\checkmark$ & $\checkmark$ & $\checkmark$ & $\checkmark$ \\
\hline Chest PNF & & & & & $\checkmark$ & $\checkmark$ & $\checkmark$ & $\checkmark$ & $\checkmark$ & $\checkmark$ & $\checkmark$ & $\checkmark$ & $\checkmark$ \\
\hline $\begin{array}{ll}\text { Lower limb } \\
\text { mobility } \\
\text { exercise }\end{array}$ & & & & & & $\checkmark$ & $\checkmark$ & $\checkmark$ & $\checkmark$ & $\checkmark$ & $\checkmark$ & $\checkmark$ & $\checkmark$ \\
\hline Ambulation & & & & & & & & $\checkmark$ & $\checkmark$ & $\checkmark$ & $\checkmark$ & $\checkmark$ & $\checkmark$ \\
\hline \multicolumn{14}{|c|}{ Outcome Measures } \\
\hline SBC on 8th day & \multicolumn{13}{|c|}{ Counts $=24$} \\
\hline $\begin{array}{l}\text { Roth Score on } \\
\text { 8th day }\end{array}$ & \multicolumn{13}{|c|}{ Duration $=8 \mathrm{sec} ;$ Highest number $=25$} \\
\hline \multirow{5}{*}{$\begin{array}{l}\text { Six-min walk } \\
\text { test (6MWT) } \\
\text { on 9th day }\end{array}$} & \multicolumn{13}{|c|}{ Total distance $=300 \mathrm{~m}$} \\
\hline & & & & & $\mathrm{SpO}_{2}$ & \multicolumn{3}{|c|}{ HR } & RPE & \multicolumn{2}{|c|}{$\begin{array}{l}\text { Blood } \\
\text { pressure } \\
\text { (BP) }\end{array}$} & \multicolumn{2}{|c|}{$\begin{array}{l}\text { Respiratory } \\
\text { rate }\end{array}$} \\
\hline & \multicolumn{4}{|c|}{ Pre } & $99 \%$ & & \multicolumn{2}{|c|}{89} & 0 & \multicolumn{2}{|c|}{$116 / 76$} & \multicolumn{2}{|l|}{22} \\
\hline & \multicolumn{4}{|c|}{ Post } & $93 \%$ & & \multicolumn{2}{|c|}{109} & 1 & \multicolumn{2}{|c|}{$128 / 80$} & \multicolumn{2}{|l|}{28} \\
\hline & \multicolumn{4}{|c|}{ Recovery to baseline } & $1 \mathrm{~min}$ & & \multicolumn{2}{|c|}{$1 \mathrm{~min} 40 \mathrm{secs}$} & 40 secs & \multicolumn{2}{|c|}{$2 \min$} & \multicolumn{2}{|c|}{$1 \mathrm{~min} 20 \mathrm{sec}$} \\
\hline PCI & \multicolumn{13}{|c|}{0.23 beats/meter } \\
\hline $\begin{array}{l}\text { One-min STS } \\
\text { test on 9th day }\end{array}$ & \multicolumn{13}{|c|}{14 reps } \\
\hline
\end{tabular}

FM -facial mask; NP- nasal prongs; PNF- proprioceptive neuromuscular facilitation; SBC- single breath count; PCI - Physiological Cost Index; RPE- rate of perceived exertion; STS- Sit to stand 


\subsection{Case 2}

A 46-year-old male, housekeeper by occupation with genu varum deformity had a past history of PTB from 2 years and had completed course of AKT. He had grade- 2 breathlessness on MMRC for 6 months which increased to grade-4 MMRC two days prior to admission. He also had loss of appetite for 6 months. He presented with acute exacerbation of obstructive airway disease. On admission, his oxygen saturation was $91 \%$ on room air he was then put-on oxygen support of $4 \mathrm{~L} / \mathrm{min}$ by facemask (FM). He was shifted to COVID ICU once he tested positive for COVID-19 on rapid antigen test. Chest X-ray revealed non-homogeneous opacities in bilateral lung fields with consolidation and fibrotic changes (Figure 2) and HRCT showed multifocal patches of sub-segmental consolidation in both lung fields predominantly in peripheral with fibro-calcific changes in apico-posterior segment of left upper lobe. The investigations and physiotherapy details are mentioned in table 3 and 4 .

Table 3 Investigations

\begin{tabular}{|l|c|c|l|}
\hline Parameters & Day after admission & Result & Interpretation \\
\hline Haemoglobin & Day 2 & 13.4 & Normal \\
\hline LDH & Day 2 & 840 & High \\
\hline CRP & Day 2 & 12.9 & Elevated \\
\hline BUN & Day 2 & 31 & Elevated \\
\hline Creatinine & Day 2 & 1.4 & Elevated \\
\hline
\end{tabular}

Table 4 Physiotherapy intervention and outcome measures

\begin{tabular}{|c|c|c|c|c|c|c|c|c|c|c|}
\hline Session No. & & 1 & 2 & 3 & 4 & 5 & 6 & 7 & 8 & 9 \\
\hline Oxygen status & & $\begin{array}{l}\text { 7L } \\
\text { FM }\end{array}$ & 2L NP & $\begin{array}{l}6 \mathrm{~L} \\
\mathrm{NP}\end{array}$ & $\begin{array}{l}\text { Room } \\
\text { air }\end{array}$ & $\begin{array}{l}\text { Room } \\
\text { air }\end{array}$ & $\begin{array}{l}\text { Room } \\
\text { air }\end{array}$ & $\begin{array}{l}\text { Room } \\
\text { air }\end{array}$ & $\begin{array}{l}\text { Room } \\
\text { air }\end{array}$ & $\begin{array}{l}\text { Room } \\
\text { air }\end{array}$ \\
\hline \multicolumn{11}{|c|}{ Vitals } \\
\hline \multirow[t]{2}{*}{ HR } & Pre & 85 & 75 & 93 & 125 & 102 & 102 & 93 & 109 & 107 \\
\hline & Post & 90 & 88 & 95 & 127 & 117 & 108 & 126 & 111 & 129 \\
\hline \multirow[t]{2}{*}{ Spo2 } & Pre & 99 & 97 & 98 & 97 & 98 & 98 & 99 & 98 & 98 \\
\hline & Post & 99 & 97 & 99 & 99 & 98 & 98 & 98 & 94 & 96 \\
\hline \multicolumn{11}{|c|}{ Physiotherapy Intervention } \\
\hline $\begin{array}{l}\text { Breathing } \\
\text { exercise }\end{array}$ & & $\checkmark$ & $\checkmark$ & $\checkmark$ & $\checkmark$ & $\checkmark$ & $\checkmark$ & $\checkmark$ & $\checkmark$ & $\checkmark$ \\
\hline $\begin{array}{l}\text { Thoracic } \\
\text { expansion }\end{array}$ & & & $\checkmark$ & $\checkmark$ & $\checkmark$ & $\checkmark$ & $\checkmark$ & $\checkmark$ & $\checkmark$ & $\checkmark$ \\
\hline Positioning & & & $\checkmark$ & $\checkmark$ & $\checkmark$ & $\checkmark$ & $\checkmark$ & $\checkmark$ & $\checkmark$ & $\checkmark$ \\
\hline $\begin{array}{l}\text { In bed } \\
\text { mobilization }\end{array}$ & & $\checkmark$ & $\checkmark$ & $\checkmark$ & $\checkmark$ & $\checkmark$ & $\checkmark$ & $\checkmark$ & $\checkmark$ & $\checkmark$ \\
\hline $\begin{array}{l}\text { Edge of the bed } \\
\text { mobilization }\end{array}$ & & & $\checkmark$ & $\checkmark$ & $\checkmark$ & $\checkmark$ & $\checkmark$ & $\checkmark$ & $\checkmark$ & $\checkmark$ \\
\hline Standing & & & $\checkmark$ & $\checkmark$ & $\checkmark$ & $\checkmark$ & $\checkmark$ & $\checkmark$ & $\checkmark$ & $\checkmark$ \\
\hline Spot marching & & & $\checkmark$ & $\checkmark$ & $\checkmark$ & $\checkmark$ & $\checkmark$ & $\checkmark$ & $\checkmark$ & $\checkmark$ \\
\hline Ambulation & & & $\begin{array}{l}\text { Bed side } \\
\text { walking }\end{array}$ & $60 \mathrm{~m}$ & - & $180 \mathrm{~m}$ & $\begin{array}{l}180 \\
\mathrm{~m}\end{array}$ & $\begin{array}{l}240 \\
\mathrm{~m}\end{array}$ & - & - \\
\hline \multicolumn{11}{|c|}{ Outcome measures } \\
\hline \multirow{5}{*}{$\begin{array}{l}\text { 6MWT on } 4^{\text {th }} \\
\text { day }\end{array}$} & \multicolumn{7}{|c|}{ Total distance $=180 \mathrm{~m}$} & & & \\
\hline & \multirow{2}{*}{\multicolumn{3}{|c|}{ Pre }} & \multicolumn{2}{|l|}{$\mathrm{SpO}_{2}$} & HR & RPE & & & \\
\hline & & & & \multicolumn{2}{|c|}{$98 \%$} & 101 & 0 & & & \\
\hline & \multicolumn{3}{|c|}{ Post } & \multicolumn{2}{|c|}{$93 \%$} & 127 & 2 & & & \\
\hline & \multicolumn{3}{|c|}{\begin{tabular}{|l|} 
Recovery to baseline \\
\end{tabular}} & \multicolumn{2}{|c|}{$2 \min 37$ secs } & $3 \mathrm{~min}$ & $1 \mathrm{~min}$ & & & \\
\hline PCI & \multicolumn{10}{|c|}{1.3 beats/meter } \\
\hline
\end{tabular}




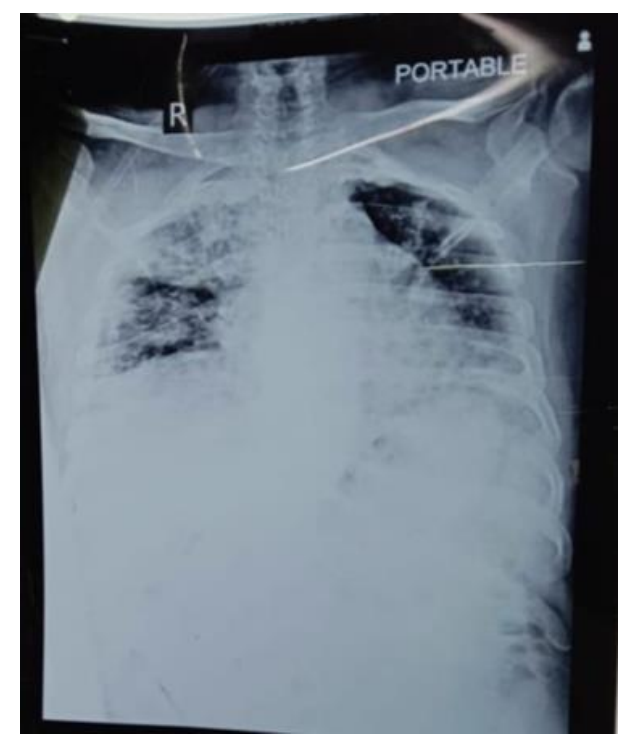

Figure 2 Chest X-ray [Case 2]

\section{Discussion}

Both the above-mentioned cases had past history of pulmonary Koch's. A study by Chen Yu et al has shown that presence of active or latent pulmonary tuberculosis increases susceptibility to COVID-19 and also disease severity. They recommended that this vulnerable group should be monitored regularly at medical centers and special medical resources should be arranged in advance for co infected patients in view of increased likelihood of rapid development of severe and critical symptoms [5]. Similarly, in these two patients close monitoring was required and supervised program was needed with medical management. Case 1 was a young patient with no other comorbidities and Case 2 was a middle-aged patient with obstructive airway disease, acute kidney injury and genu varum. Both had CO*RADS 5 with CT severity score of 10/25 for case 1 and 15/25 for case 2 indicating moderate lung involvement. Case 1 was able to maintain his saturation with 2 liters supplemental oxygen initially but Case 2 needed oxygen support of 7 liters to maintain saturation at optimal level of $95 \%$. Case 1 required oxygen support for 6 days and Case 2 for 4 days after which they were shifted to room air.

Case 1 was initially anxious about performing exercises. He needed intense counselling and was educated about the importance of physiotherapy and the need to perform exercises regularly. In bed mobility with deep breathing exercises were started. Breathing control was used to control cough triggered by deep breathing. This led to significant increase in his oxygen saturation and reduction in the respiratory rate. As patient's vital parameters became stable, exercises were progressed to thoracic expansion exercise, edge of bed mobility, lower limb mobility and strengthening. Spot marching was introduced in patient's treatment protocol along with proning. Gradually, awake proning time was increased along with PNF stretches in prone to increase posterior basal lung expansion. Later on, walking program was introduced with adequate rest pause as patient was getting breathless and fatigued easily. Oxygen saturation was monitored during each activity. Total ICU stay was of 12 days. On his pre discharge assessment he walked 300 meters on 6 Minute walk test without any rest pause. Single breath count (SBC) was 24 and it was also given as an exercise stimulus to perform every day. He performed 14 repetitions of 1 Minute sit to stand test (1MSTS) which falls below normal range which is 25-37 reps/min for men above 24 years of age [13]. Roth score strongly correlates with severity as determined by hypoxia [14]. His total duration was 8 seconds and highest count was 25 indicating saturation above $95 \%$ on $8^{\text {th }}$ day after admission which it was.

In Case 2, as patient had Genu Varum deformity it was difficult for him to achieve prone position initially where quarter prone positioning was given and then as he gained confidence, active prone position was achieved gradually. On second day, his oxygen support was reduced to 2 liters, thoracic expansion exercises, edge of bed mobility exercises, upper and lower limb strengthening exercises were introduced in the program, emphasizing more on upper extremity and nonweight bearing lower limb exercises considering his knee pain and deformity. He was using accessory muscles for respiration and the same muscles like trapezius, serratus anterior had to work for upper limb exercises resulting in dissynchronized breathing causing early fatigue and desaturation by $4 \%$ but always above $94 \%$. Hence the exercises had to be performed with pauses as and when required. The pauses were more in number in case 2 as compared to case 1 for reason mentioned above. Walking program was initiated on very next day of admission with adequate rest pauses 
in between, on third physiotherapy session he walked 60 meters with 2 liters oxygen support with complaints of fatigue. However, he walked only 180 meters off $\mathrm{O}_{2}$ during $6 \mathrm{MWT}$ which was taken prior to discharge. With monitored walking programme, patient covered total distance of 240 meters in the next sessions. However, after that he had knee pain and fatigue thus exercise regime without walking programme was followed during next sessions. One-minute sit to stand test was not performed owing to knee pain.

A tailor-made exercise program was given along with constant monitoring which helped them in their recovery along with their medical management. Depending on the changes in medical management, appropriate variation in physiotherapy management was given. For instance, in Case 1 when Remdesivir was administered, mobilization and ambulation was not advisable due to its side effects of fatigue and vomiting [15].The treatment program was focused more on breathing control and in-bed mobility. In case 2 because of genu varum and knee pain he was given more repetitions of upper limb mobility and non-weight bearing lower limb exercises rather than focusing on walking. A constant dialogue was maintained with the medical team to ensure smooth recovery.

Both the subjects had $91 \%$ oxygen saturation on admission and they required oxygen support to obtain and maintain saturation at optimal level. Both the cases had average hospital stay and took 9-12 days to discharge from hospital. A systematic review by Rees, Nightingale, Jafari et al of early evidence of length of stay in patients of covid-19 in hospitals states that median length of stay of hospital for countries outside China was 4-21 days[16]. It was very encouraging to note that the supplemental oxygen requirement of both the patients reduced in spite of progression of the intensity of training day by day. (Figure 3)

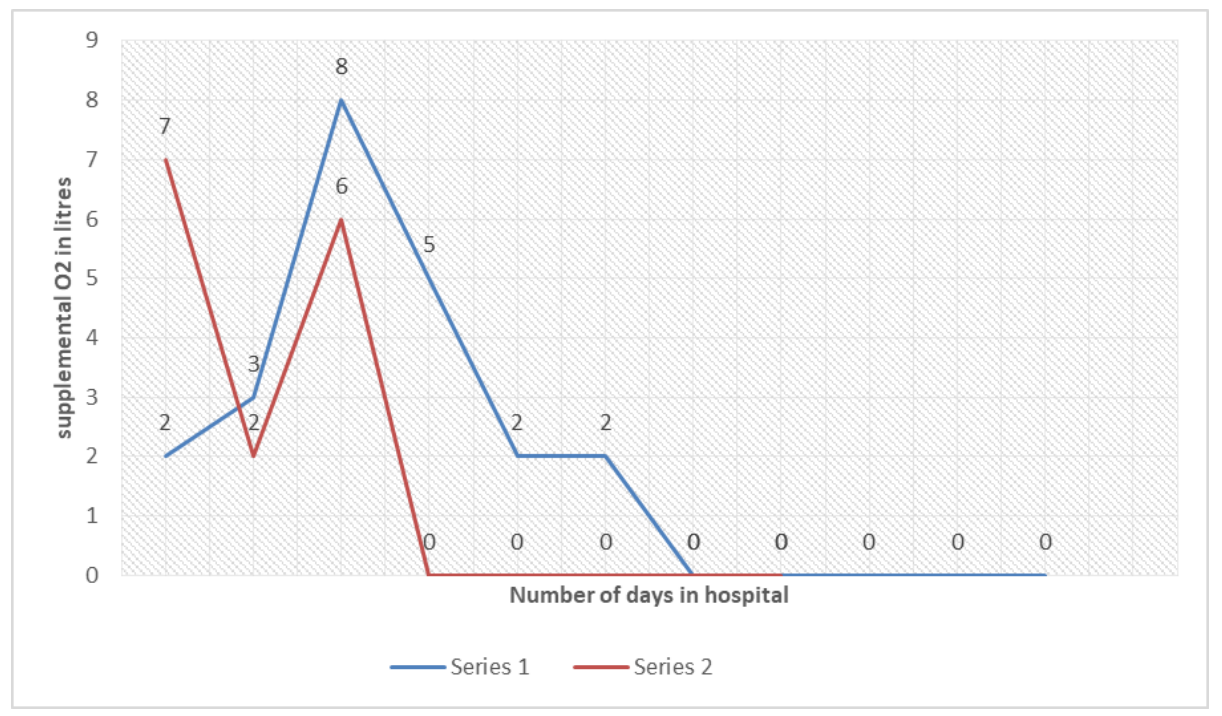

Figure 3 Decline in supplemental oxygen with progress in sessions

At the time of discharge when six-minute walk test was performed, it was observed that the distance covered by them was less than 340 meters. This indicates poor functional capacity [17]. In these two cases Physiological cost index (PCI) was calculated for evaluation of energy consumption while walking. PCI proposed by Mac Gregor is a simple and straightforward method to estimate the energy expenditure index. It is a ratio of heart rate per meter walked. PCI is found to be economical at comfortable walking speed and it increases with slower or faster speeds of walking [18]. In Case 1 PCI was 0.23 beats/meter and 1.3 beats/meter in case 2 . Thus Case 2 consumed more energy for walking. There was significant drop in 02 saturation ( $>4 \%$ ) during walking which recovered in 1 to 3 minutes this indicates that further pulmonary rehabilitation is required with close monitoring of saturation and adequate pauses $[19,20]$. 


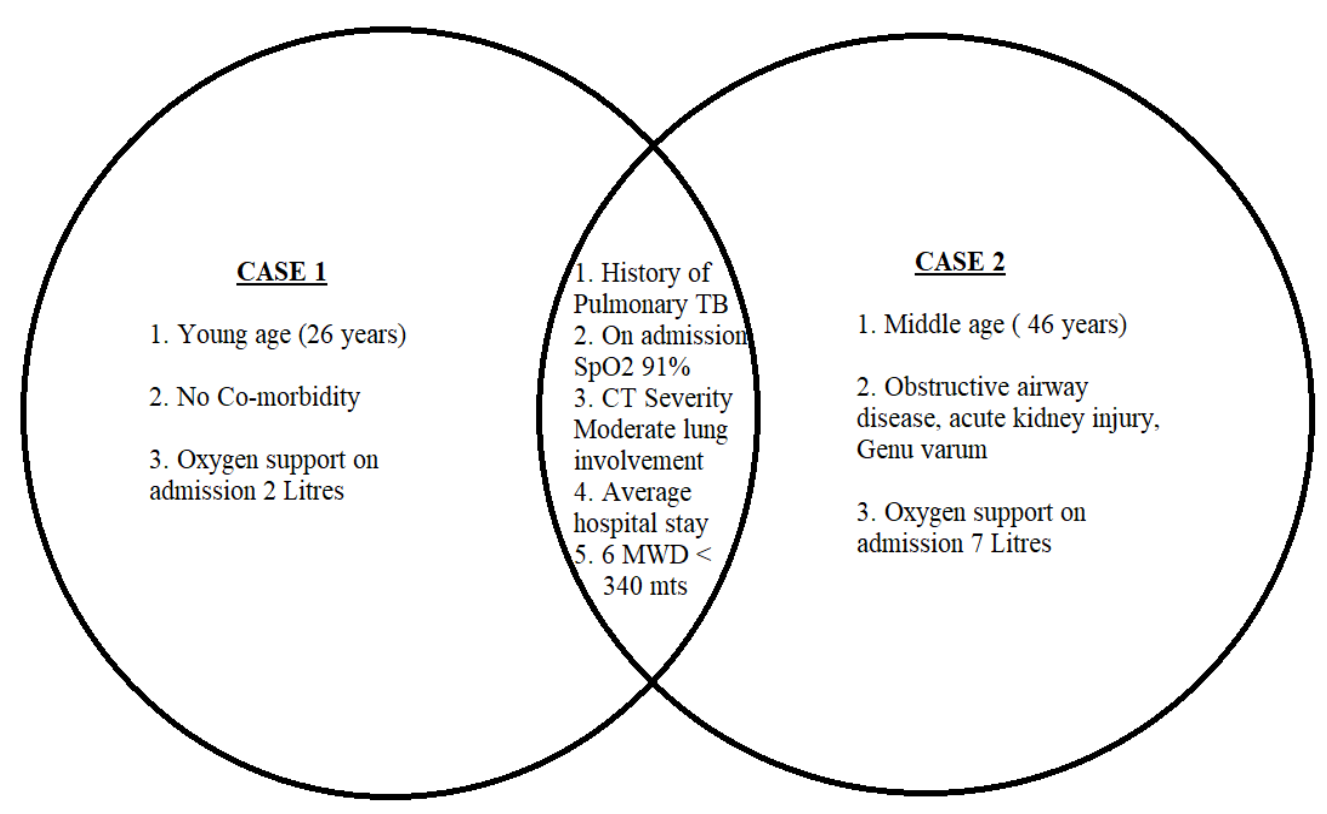

Figure 4 Similarities and differences in Case 1 and Case 2

Figure 4 shows the similarities and differences of the two patients described above. For rehabilitation of these two COVID-19 patients with post PTB sequelae, appropriate early physiotherapy intervention was given and it was modified in accordance with their medical management. This helped in their safe and timely recovery. However, their predischarge assessment still showed reduced functional capacity which highlights the need for continuing pulmonary rehabilitation.

\section{Conclusion}

A well planned individually tailored Physiotherapy program as an adjuvant to Medical management is effective in early recovery of COVID-19 patients with pre-existing healed Pulmonary Tuberculosis.

\section{Compliance with ethical standards}

\section{Acknowledgement}

We acknowledge Dr. Hemant Deshmukh, Dean Seth GS Medical College, Professor Saraswati Iyer, Head Physiotherapy School and Centre for their support.

\section{Disclosure of conflict of interest}

The authors declare no conflict of interest.

\section{Statement of informed consent}

Ethical considerations were followed while documenting the case. Informed consent was obtained from both the patients. There is no disclosure of identity.

\section{References}

[1] Brosnahan SB, Jonkman AH, Kugler MC, Munger JS, Kaufman DA. COVID-19 and Respiratory System Disorders: Current Knowledge, Future Clinical and Translational Research Questions. Arterioscler Thromb Vasc Biol. Nov 2020; 40(11): 2586-2597. 
[2] Verma CV, Arora RD, Shetye J, Karnik ND et al. Guidelines of physiotherapy management in acute care of COVID19 at dedicated COVID center in Mumbai. The Journal of Indian Association of Physiotherapists. 2020; 14(1): 5560 .

[3] Jiandani M, Agarwal B, Baxi G, Kale S, Pol T, Bhise A et al. Expert Consensus and Recommendation for Physiotherapy Management of COVID-19 in Indian Set Up. The Indian Journal of Critical Care Medicine. 2020.

[4] Tobin MJ. Basing Respiratory Management of COVID-19 on Physiological Principles. Am J Respir Crit Care Med. 2020; 201(11): 1319-1320.

[5] Liu Y, Bi L, Chen Y, Wang Y, Fleming J, Yu Y, Gu Y, Liu C, Fan L, Wang X, Cheng M. Active or latent tuberculosis increases susceptibility to COVID-19 and disease severity. MedRxiv. 1 Jan 2020.

[6] Chadha VK. Tuberculosis epidemiology in India: a review. Int J Tuberc Lung Dis. Oct 2005; 9(10): $1072-82$.

[7] Cole G, Miller D, Ebrahim T, Dreyden T, Simpson R, Manie S. Pulmonary impairment after tuberculosis in a South African population. S Afr J Physiother. 30 Jun 2016; 72(1): 307.

[8] Zheng Z, Peng F, Xu B, Zhao J, Liu H, Peng J, Li Q, Jiang C, Zhou Y, Liu S, Ye C, Zhang P, Xing Y, Guo H, Tang W. Risk factors of critical \& mortal COVID-19 cases: A systematic literature review and meta-analysis. J Infect. Aug 2020; 81(2): e16-e25.

[9] Musso M, Di Gennaro F, Gualano G, Mosti S, Cerva C, Fard SN, Libertone R, Di Bari V, Cristofaro M, Tonnarini R, Castilletti C, Goletti D, Palmieri F. Concurrent cavitary pulmonary tuberculosis and COVID-19 pneumonia with in vitro immune cell anergy. Infection. 21 Jan 2021; 1-4.

[10] Gao Y, Liu M, Chen Y, Shi S, Geng J, Tian J. Association between tuberculosis and COVID-19 severity and mortality: A rapid systematic review and meta-analysis. J Med Virol. Jan 2021; 93(1): 194-196.

[11] Tadolini M, Codecasa LR, García-García JM, Blanc FX, Borisov S, Alffenaar JW et al. Active tuberculosis, sequelae and COVID-19 co-infection: first cohort of 49 cases. Eur Respir J. 9 Jan 2020; 56(1): 2001398.

[12] Yousaf Z, Khan AA, Chaudhary HA, Mushtaq K, Parengal J, Aboukamar M, Khan MU, Mohamed MFH. Cavitary pulmonary tuberculosis with COVID-19 coinfection. IDCases. 2020; 22: e00973.

[13] Strassmann A, Steurer-Stey C, Lana KD, Zoller M, Turk AJ, Suter P, Puhan MA. Population-based reference values for the 1-min sit-to-stand test. Int J Public Health. Dec 2013; 58(6): 949-53.

[14] Sardesai I, Grover J, Garg M, Nanayakkara PWB, Di Somma S, Paladino L, Anderson HL 3rd, Gaieski D, Galwankar SC, Stawicki SP. Short Term Home Oxygen Therapy for COVID-19 patients: The COVID-HOT algorithm. J Family Med Prim Care. 30 Jul 2020; 9(7): 3209-3219.

[15] Eastman RT, Roth JS, Brimacombe KR, Simeonov A, Shen M, Patnaik S, Hall MD. Remdesivir: A Review of Its Discovery and Development Leading to Emergency Use Authorization for Treatment of COVID-19. ACS Cent Sci. 27 May 2020; 6(5): 672-683.

[16] Rees EM, Nightingale ES, Jafari Y. et al. COVID-19 length of hospital stay: a systematic review and data synthesis. BMC Med. 2020; 18: 270.

[17] Villalba WO, Sampaio-Barros PD, Pereira MC, Cerqueira EM, Leme CA Jr, Marques-Neto JF, Paschoal IA. Six-minute walk test for the evaluation of pulmonary disease severity in scleroderma patients. Chest. Jan 2007; 131(1): 21722 .

[18] Rana BS, Pun M. Estimation of Physiological Cost Index as an Energy Expenditure Index using MacGregor's Equation. JNMA J Nepal Med Assoc. Jul-Sep 2015; 53(199): 174-9.

[19] Sakai Y, Yamamoto S, Hoshina M. et al. Using Sp02 Recovery Index after a 6-Minute Walk Test to Predict Respiratory-Related Events in Hospitalized Patients with Interstitial Pneumonia. Sci Rep. 2019; 9: 15226.

[20] FROTA, Aline Xavier et al. Functional capacity and rehabilitation strategies in Covid-19 patients: current knowledge and challenges. Rev. Soc. Bras. Med. Trop. [online]. 2021; 54. 